NIHARIKA SAMALA (Orcid ID : 0000-0002-1993-5223)

ARUN J. SANYAL (Orcid ID : 0000-0001-8682-5748)

NAGA CHALASANI (Orcid ID : 0000-0003-2359-6030)

Article type : Original Article

\title{
Clinical Characteristics and Outcomes of Mild to Moderate Alcoholic Hepatitis
}

\author{
Niharika Samala, M.D. ${ }^{1}$, Samer Gawrieh, M.D. ${ }^{1}$, Qing Tang, M.S. ${ }^{2}$, Spencer G. Lourens, \\ Ph.D. ${ }^{2}$, Vijay H. Shah, M.D. ${ }^{3}$, Arun J. Sanyal, M.D. ${ }^{4}$, Suthat Liangpunsakul, M.D. ${ }^{1,5,6}$, \\ Naga Chalasani, M.D. ${ }^{1}$
}

\begin{abstract}
${ }^{1}$ Division of Gastroenterology and Hepatology, Department of Medicine, Indiana University School of Medicine, Indianapolis, Indiana;'2Department of Biostatistics, Indiana University School of Medicine, Indianapolis, Indiana; ${ }^{3}$ Division of Gastroenterology and Hepatology, Department of Medicine, Mayo Clinic, Rochester, Minnesota; ${ }^{4}$ Division of Gastroenterology, Department of Internal Medicine, Virginia Commonwealth University, Richmond, Virginia ${ }^{5}$ Roudebush Veterans Administration Medical Center, Indianapolis, Indiana; ${ }^{6}$ Department of Biochemistry and Molecular Biology, Indiana University School of Medicine, Indianapolis, Indiana
\end{abstract}

Short title: Moderate Alcoholic Hepatitis

Source of Funding: The Translational Research and Evolving Alcoholic Hepatitis Treatment (TREAT) Consortium was supported by the National Institute on Alcohol Abuse and Alcoholism (NIAAA) (grants 5U01AA021883-04, 5U01AA021891-04, 5U01AA021788-04, 5U01AA021840-04).

Disclosures: Drs. Chalasani and Sanyal have number of consulting agreements and research grants from pharmaceutical companies but none are deemed relevant for this paper. Dr. Shah has research grant support from Generon, but is not relevant for this paper. Other authors declare no conflicts of interest.

This is the author's manuscript of the article published in final edited form as: 
Roles of authors

\section{Corresponding Author} \\ Naga Chalasani M.D. \\ Division of Gastroenterology and Hepatology \\ Indiana University School of Medicine \\ 702 Rotary Circle, Suite 225 \\ Indianapolis, Indiana, 46202-5175 \\ Email: nchalasa@iu.edu
}

All authors have read and approved the manuscript for submission. All have made a substantial contribution to the conception, design, gathering, analysis and/or interpretation of data and a contribution to the writing and intellectual content of the article; and acknowledge that they have exercised due care in ensuring the integrity of the work.

\title{
Members of the TREAT Consortium
}

TREAT Consortium: The consortium was established with the funding from the NIH/NIAAA to study the pathogenesis and new treatments for $\mathrm{AH}$. It consists of three academic centers in the US: Indiana University (Indianapolis, IN), Mayo Clinic (Rochester, MN), and Virginia Commonwealth University (Richmond, VA).

Indiana University, Indianapolis, IN: David Crabb, MD, Naga Chalasani, MD, Suthat Liangpunsakul, MD, Barry Katz, PhD, Spencer Lourens, PhD, Andy Borst, BS, Ryan Cook, $\mathrm{MPH}$, Andy Qigui Yu, PhD, David Nelson, PhD, Romil Saxena, MD, Jennifer Lehman, RN, Kayla Gelow, BS.

Mayo Clinic, Rochester, MN: Vijay Shah, MD, Gregory Gores, MD, Patrick Kamath, MD, Vikas Verma, PhD, Sarah Wilder, RN, BSN, Amy Olofson, RN, Amanda Schimek

Virginia Commonwealth University, Richmond, VA: Arun Sanyal, MD, Puneet Puri, MD, Susan Walker, RN, MSN

The National Institute of Alcohol Abuse and Alcoholism (NIAAA): Scientific/Program Collaborator: Svetlana Radaeva, PhD.

\section{Abstract}

Introduction \& Aim: Much is known about alcoholic hepatitis $(\mathrm{AH})$ that is severe enough to require hospitalization. The characteristics of individuals with alcoholic hepatitis presenting with mild to moderate severity are not well understood. In this study we investigated the risk factors, characteristics, and outcomes of mild to moderate $\mathrm{AH}$.

Methods: Two hundred and fifty five Individuals with $\mathrm{AH}$ enrolled into a multicenter, prospective, observational study between 12/2014 and 4/2018 were included. Participants 
were seen at enrollment, 6 months, and 12 months. Mild to moderate $A H(M-A H)$ was defined as MELD $\leq 20$ at presentation whereas severe $A H$ as MELD $\geq 21$.

Results: One hundred individuals had $\mathrm{M}-\mathrm{AH}$ whereas 155 had severe $\mathrm{AH}$. Individuals with $\mathrm{M}-\mathrm{AH}$ were older (49 vs 44 years, $\mathrm{p}=0.01$ ), had lower BMl (27 vs $31 \mathrm{~kg} / \mathrm{m} 2, \mathrm{p}=0.0007$ ) and more likely to be male (68\% vs $55 \%, \mathrm{p}=0.046$ ) compared to severe $\mathrm{AH}$ group. A higher proportion in $\mathrm{M}-\mathrm{AH}$ group consumed coffee in the last 5 years compared to the severe $\mathrm{AH}$ (29\% vs $18 \%, p=0.03)$, and fewer had PNPLA3 risk allele $\mathrm{G}(\mathrm{p}=0.019)$ compared to the severe $\mathrm{AH}$ group. Average drinks per drinking day (12.9 vs $10.7, p=0.13$ ) and total number of drinks in last 30 day period ( 331 vs $280, p=0.14$ ) were not different between two groups. Compared to severe $\mathrm{AH}$, patients with $\mathrm{M}-\mathrm{AH}$ had significantly lower mortality at 30 days $(2 \%$ vs. $13.6 \%$ ), 90 days ( $3 \%$ vs. $22.6 \%$ ), and 12 months (10.4\% vs. $31.4 \%)$ ( $p<0.001$ for all).

Conclusions: Individuals with mild to moderate $\mathrm{AH}$ were older, less obese, drank coffee more often and carried more favorable PNPLA3 genotype compared to severe $\mathrm{AH}$, despite similar alcohol consumption. Mild to moderate $\mathrm{AH}$ had substantial mortality with one in ten dying by 12 months.

Key Words: Alcoholic hepatitis; PNPLA3; Coffee drinking; MELD

\section{Introduction}

Alcoholic liver disease (ALD) represents a clinical and histopathological spectrum ranging from simple steatosis, alcoholic steatohepatitis, and cirrhosis (Sozio and Crabb, 2008) Alcoholic hepatitis $(\mathrm{AH})$, the most severe clinical manifestation of ALD among excessive drinkers, is characterized by sudden onset of jaundice and liver-related complications. It is associated with a high short term mortality ranging $15 \%$ to $35 \%$ within the first month after the diagnosis (Liangpunsakul, 2011; Maddrey et al., 1978; Orntoft et al., 2014) However, 
majority of these estimates have come from hospitalized patients with severe $\mathrm{AH}$ who are participating in clinical trials. There are many patients with less severe $\mathrm{AH}$ who are not hospitalized and their clinical characteristics and outcomes are not well understood.

Model for End Stage Liver Disease (MELD) score, initially derived from a study to determine predictors of survival in a cohort of patients who underwent transjugular intrahepatic portosystemic shunt (TIPS), has been shown to be relevant in predicting 30- and 90-day mortality in patients with $\mathrm{AH}$ with similar sensitivity and specificity as Maddrey Discriminant function. (Dunn et al., 2005; Malinchoc et al., 2000) MELD score greater than 20 in $\mathrm{AH}$ patients is associated with a 90 -day mortality rate of more than $20 \%$. Therefore, patients with $\mathrm{AH}$ whose MELD > 21 are generally considered to have severe $\mathrm{AH}$. (Dunn et al., 2005) (Dunn et al., 2005) Hence this serves as a good cut-off to categorize patients into those who present with severe and the rest who present with mild to moderate $\mathrm{AH}$. Knowing the characteristics of individuals who present with mild-moderate $\mathrm{AH}$ would be instructive in understanding risk factors for severe presentation.

We have shown previously that PNPLA3 G allele among heavy drinkers was associated with alcoholic hepatitis. (Liangpunsakul et al., 2016) We also saw a lower prevalence of regular coffee consumption among heavy alcohol drinkers who develop AH. (Lianpunsakul, 2017)

We wanted to determine the clinical features, environmental risk factors such as coffee consumption and genetic risk factors such as PNPLA3 of individuals with AH who present with mild to moderate $\mathrm{AH}(\mathrm{M}-\mathrm{AH})$ compared to severe $\mathrm{AH}$. In this study, we report the risk factors, clinical characteristics and outcomes of patients presenting with mild to moderate $\mathrm{AH}(\mathrm{M}-\mathrm{AH})$ who are enrolled into a prospective study and followed for twelve months following their enrollment.

This article is protected by copyright. All rights reserved. 


\section{Methods}

The study consisted of individuals who were enrolled into TREAT 001 (NCT 02172898) study between 12/2014 and 04/2018. TREAT 001 was a multicenter, prospective, observational study of individuals with $\mathrm{AH}$ and heavy drinking controls. The design of this study has been previously described in detail (Liangpunsakul et al., 2016), but in brief, individuals with $\mathrm{AH}$ and heavy drinking controls without liver disease meeting predefined eligibility criteria were enrolled at three large liver centers in the United States and were followed for 12 months. This study was approved by the Institutional Review Boards at each of the participating centers and all participants signed an informed consent. Individuals who are included in this analysis have been part of several other publications by our group.

Demographic data, past medical history, clinical characteristics, questionnaires and blood samples were collected at the time of enrollment. Alcohol Use Disorders Identification Test (AUDIT) and the Time Line Follow-Back (TLFB) were used to characterize the alcohol consumption data. Coffee questionnaire captured duration and quantity per day of coffee and tea consumption. PNPLA3 genotype was determined according to methods previously described. The study protocol included an enrollment visit and visits at 6 and 12 months. Death was ascertained by direct family contact and in case of individuals who were lost to follow up it was through the National Death Registry. All subjects with a MELD score $\leq 20$ at presentation were defined as having mild to moderate $A H(M-A H)$ and those with MELD $\geq 21$ was defined as severe $\mathrm{AH}$.

\section{Statistical analysis}

Pearson's chi-square test and two-sample t-tests were employed to determine the differences of the categorical and continuous variables, respectively, between patients with moderate and severe $\mathrm{AH}$. When sample sizes were small, Fisher's exact test was applied instead of Pearson's chi-square test. Survival analysis between patients with moderate and

This article is protected by copyright. All rights reserved. 
severe $\mathrm{AH}$ was estimated using the Kaplan-Meier method, and the differences were compared using the log-rank test. A p-value $<0.05$ was considered statistically significant.

\section{Results}

During the study period, 255 individuals with $\mathrm{AH}$ were enrolled, of whom 100 had $\mathrm{M}-\mathrm{AH}$ and 155 had severe $\mathrm{AH}$. Baseline demographics and selected clinical characteristics of two groups are shown in Table 1. Among individuals with $\mathrm{M}-\mathrm{AH}$, the MELD score was between 11 and 20 in 93, 10 in 3, and 9 in 4 participants. Individuals with $\mathrm{M}-\mathrm{AH}$ were older (49 vs 44 years, $p=0.01)$ and were more likely to be male ( $68 \%$ vs $55 \%, p=0.046)$ when compared to those with severe $\mathrm{AH}$. They also had a significantly lower BMl compared to those with severe AH (27 vs $\left.31 \mathrm{~kg} / \mathrm{m}^{2}, p<0.05\right)$. Although patients with $M-A H$ had higher levels of ALT (82 vs $48 \mathrm{U} / \mathrm{L}, \mathrm{p}<0.0001$ ) and AST (163 vs $126 \mathrm{U} / \mathrm{L}, \mathrm{p}=0.001$ ), they demonstrated less severe liver synthetic dysfunction, as reflected in higher serum albumin (3.0 vs $2.7 \mathrm{gm} / \mathrm{dL}, \mathrm{p}$ $<0.05$ ), lower total bilirubin (6 vs $15 \mathrm{mg} / \mathrm{dL}, \mathrm{p}<0.0001$ ) and lower international normalized ratio $(1.4$ vs $2.1, p<0.0001)$

A higher proportion of individuals with $\mathrm{M}-\mathrm{AH}$ were coffee drinkers in last five years compared to those with severe $\mathrm{AH}(29 \%$ vs $18 \%, \mathrm{p}=0.03$. (Table 2) There was no significant difference in average drinks per drinking day $(12.9$ vs $10.7, p=0.13)$ or total number of drinks in the last 30 days ( 331 vs $280, p=0.14$ ) between two groups. (Table 2 )

Fewer individuals with $\mathrm{M}-\mathrm{AH} \mathrm{AH}$ carried the PNPLA3 genotypes with high risk $\mathrm{G}$ allele (GG and $\mathrm{GC}$ ) compared to those with severe $\mathrm{AH}$. The frequency of PNPLA3 CC, CG, and GG genotypes in $\mathrm{M}-\mathrm{AH}$ were $55 \%, 38 \%$, and $7 \%$ respectively and it was significantly different from severe $\mathrm{AH}$ group (CC: $34 \%$, CG: $52 \%$, and GG: 13\%, $p=0.02$ ).

There was a significant interaction between coffee drinking and the PNPLA3 genotype $(p=0.0037)$. (Table 3) Among those carrying high risk PNPLA3 G allele, fewer proportion of coffee consumers presented with severe $\mathrm{AH}$ compared to non-consumers of coffee. $(52.2 \%$ 
vs $74 \%$ respectively) Even among those with favorable PNPLA3 genotype profile (CC), fewer proportion of coffee consumers presented with severe $\mathrm{AH}$ compared to nonconsumers of coffee. (33.3\% vs 53.6\%) (Table 3).

Compared to individuals with severe $\mathrm{AH}$, patients with $\mathrm{M}-\mathrm{AH}$ had significantly lower mortality at 30 days ( $2 \%$ vs. $13.6 \%, p<0.001), 90$ days ( $3 \%$ vs. $22.6 \%, p<0.001)$, and 12 months (10.4\% vs. $31.4 \%, p<0.001$ ) ( $p<0.001$ by Log-rank test). (Figure 1) The causes of death for individuals with $\mathrm{M}-\mathrm{AH}$ were complications of end stage liver disease in 5 , unknown causes in 2, complications from accidental falls in 2 , clostridium difficile colitis in 1.

\section{Discussion}

Our study shows that a substantial proportion of $\mathrm{AH}$ patients $(40 \%)$ seeking medical attention have mild to moderate $\mathrm{AH}$, as defined by a MELD score $\leq 20$. A majority of them with M-AH had MELD scores between 11 and 20 with a small minority presenting with MELD less than 11. Individuals with $\mathrm{M}-\mathrm{AH}$ in our study were found to have lower $\mathrm{BMI}$ and fewer females compared to those with severe $\mathrm{AH}$. While excess body weight and female sex were previously shown to be associated with an increased risk for $\mathrm{AH}$ (Liangpunsakul et al., 2016), our study is the first to observe that female sex and overweight are associated with severity of $\mathrm{AH}$ as well.

Lack of significant relationship between amount of alcohol consumed or duration of alcohol consumption by heavy drinkers and the disease severity is interesting. These results are consistent with our previous observation that the degree of alcohol consumption was not associated with the risk for $\mathrm{AH}$ among heavy drinkers.(Liangpunsakul et al., 2016) This suggests that once the level and duration of alcohol consumption reach a threshold it is the demographic, genetic, and environmental factors, which determine the risk for developing $\mathrm{AH}$ as well as its severity at presentation.

This article is protected by copyright. All rights reserved. 
In addition to the demographic differences, we observed significant differences in environmental risk factors. Higher proportion of individuals with $\mathrm{M}-\mathrm{AH}$ consumed coffee in the last five years compared to those with severe $\mathrm{AH}$. This very interesting finding corroborates previous observations of coffee consumption as a protective risk modifier in development of hepatic fibrosis after adjusting for age, sex, BMI and liver disease diagnosis and alcohol intake. (Liu et al., 2015; Molloy et al., 2012)

We and others have previously shown that PNPLA3 G allele is associated with alcoholic cirrhosis and alcoholic hepatitis. $(10,11)$ Our data suggests that PNPLA3 G allele may also be associated with severity of $\mathrm{AH}$. We have previously shown an interaction between PNPLA3 genotype and coffee drinking and the risk for $\mathrm{AH}$ among heavy drinkers. (Liangpunsakul, 2017) The current study suggests a similar interaction between coffee drinking and PNPLA3 genotype in modifying the AH severity. Coffee consumption in high risk PNPLA3 allele carriers, reduced the proportion of individuals presenting with severe $\mathrm{AH}$ to that seen in low risk PNPLA3 allele carriers who were not coffee consumers. Coffee consumption among the low risk PNPLA3 allele carriers, drove this proportion further down.

Although individuals with moderate $\mathrm{AH}$ fared better than those with severe $\mathrm{AH}$, their mortality was still substantial with one year mortality of $10.4 \%$. Another important observation is that a half of deceased individuals with mild to moderate $\mathrm{AH}$ died from reasons other than liver failure such as accidental falls (in 20\%), infection (10\%) and unknown (20\%). Different strategies will likely be needed to prevent these non-hepatic causes of death in this patient population.

In summary, our data shows that in a population of $\mathrm{AH}$ patients, close to $40 \%$ present with $\mathrm{M}-\mathrm{AH}$. These patients are older, less likely to be female and have lower BMI compared to patients presenting with severe $\mathrm{AH}$. Although their level of alcohol consumption was similar, patients with $\mathrm{M}-\mathrm{AH}$ more commonly report coffee consumption and have lower frequency of carrying high risk PNPLA3 G allele compared to severe $\mathrm{AH}$, suggesting the role of genetic 
and environmental factors in modifying disease severity. Their mortality is substantial with 1year mortality of $10.4 \%$, with half of deaths due to non-liver related causes.

Table 1: Selected Demographic and Laboratory Characteristics of Individuals With Mild to Moderate and Severe AHף

\begin{tabular}{|l|c|c|c|}
\hline & $\begin{array}{c}\text { Mild to } \\
\text { Moderate AH } \\
(\mathbf{n = 1 0 0})\end{array}$ & $\begin{array}{c}\text { Severe AH } \\
(\mathbf{n = 1 5 5 )}\end{array}$ & P-value \\
\hline Age (years) & $49.0 \pm 10.4$ & $44.5 \pm 10.9$ & 0.001 \\
\hline Male (\%) & 68 & 55.5 & 0.046 \\
\hline White (\%) & 83 & 89 & 0.16 \\
\hline PTSD (\%) & 37 & 32 & 0.55 \\
\hline BMI (Kg/m ${ }^{2}$ ) & $27.5 \pm 6.0$ & $30.8 \pm 8.2$ & 0.0007 \\
\hline WBC (x 10 ${ }^{3} / \mathbf{m m}^{3}$ ) & $8.4 \pm 5.4$ & $13.5 \pm 8.4$ & $<.0001$ \\
\hline Hemoglobin (gm/dl) & $10.3 \pm 2.0$ & $10.0 \pm 2.0$ & 0.17 \\
\hline Platelet (x 10 /mm $^{3}$ ) & $131.9 \pm 82.5$ & $147.2 \pm 83.1$ & 0.15 \\
\hline $\begin{array}{l}\text { Total Bilirubin } \\
\text { (mg/dl) }\end{array}$ & $5.7 \pm 4.4$ & $19.5 \pm 10.9$ & $<.0001$ \\
\hline INR & $1.4 \pm 0.3$ & $2.1 \pm 0.6$ & $<.0001$ \\
\hline AST (U/L) & $162.9 \pm 110.5$ & $126.5 \pm 65.6$ & 0.0011 \\
\hline ALT (U/L) & $81.8 \pm 82.5$ & $48.3 \pm 35.8$ & $<.0001$ \\
\hline Albumin (g/dl) & $3.0 \pm 0.8$ & $2.7 \pm 0.6$ & 0.009 \\
\hline Creatinine (mg/dl) & $0.7 \pm 0.2$ & $1.3 \pm 1.4$ & $<.0001$ \\
\hline MELD score & $16.1 \pm 3.1$ & $27.2 \pm 5.8$ & $<.0001$ \\
\hline & & & \\
\hline
\end{tabular}

TValues are shown as means \pm standard deviation unless otherwise specified Abbreviations; BMI: Body Mass lindex; WBC: White Blood Cells; INR; International Normalized Ratio; MELD score: Model for End Stage Liver Disease. 
Table 2: Coffee and Alcohol Consumption of Individuals with Mild to Moderate and Severe $\mathrm{AH} \uparrow$

\begin{tabular}{|c|c|c|c|}
\hline & $\begin{array}{c}\text { Mild to } \\
\text { Moderate AH } \\
(n=100)\end{array}$ & $\begin{array}{c}\text { Severe AH } \\
(n=155)\end{array}$ & P-value \\
\hline $\begin{array}{l}\text { Years of alcohol } \\
\text { drinking }\end{array}$ & $25.6 \pm 14.5$ & $25.1 \pm 10.6$ & 0.87 \\
\hline $\begin{array}{l}\text { Average alcohol Drinks } \\
\text { per Drinking Day }\end{array}$ & $12.9 \pm 11.8$ & $10.7 \pm 8.0$ & 0.13 \\
\hline $\begin{array}{l}\text { Alcohol drinks per last } \\
30 \text { day period }\end{array}$ & $331.5 \pm 273.3$ & $280.1 \pm 209.6$ & 0.15 \\
\hline $\begin{array}{l}\text { Average alcohol } \\
\text { consumed per drinking } \\
\text { day (Grams) }\end{array}$ & $193.2 \pm 177.0$ & $160.5 \pm 119.9$ & 0.135 \\
\hline Coffee drinking (\%) & 29 & 18 & 0.035 \\
\hline $\begin{array}{l}\text { Years of drinking } \\
\text { coffee? (if } \geq 5 \text { years) }\end{array}$ & $25.6 \pm 14.5$ & $25.1 \pm 10.6$ & 0.8748 \\
\hline $\begin{array}{l}\text { Cups of caffeinated } \\
\text { coffee per day (if } \geq 5 \\
\text { years) }\end{array}$ & $4.6 \pm 8.1$ & $2.3 \pm 1.9$ & 0.1439 \\
\hline
\end{tabular}

I Values are shown as means \pm standard deviation unless otherwise specified 
TABLE 3: The relationship between PNPLA3 genotypes and coffee consumption and the severity of $\mathrm{AH}(\mathrm{N}=174)$

\begin{tabular}{|l|c|c|c|}
\hline & $\begin{array}{c}\text { Mild to moderate } \\
\text { AH } \\
(\mathbf{n = 6 9 )}\end{array}$ & $\begin{array}{c}\text { Severe AH } \\
(\mathbf{n}=105)\end{array}$ & P-value \\
\hline PNPLA3 CC genotype + Coffee drinking & $12(66.7 \%)$ & $6(33.3 \%)$ & 0.0037 \\
\hline $\begin{array}{l}\text { PNPLA3 CC genotype + No coffee } \\
\text { drinking }\end{array}$ & $26(46.4 \%)$ & $30(53.6 \%)$ & \\
\hline $\begin{array}{l}\text { PNPLA3GG/GC genotype + Coffee } \\
\text { drinking }\end{array}$ & $11(47.8 \%)$ & $12(52.2 \%)$ & \\
\hline $\begin{array}{l}\text { PNPLA3GG/GC genotype + No coffee } \\
\text { drinking }\end{array}$ & $20(26.0 \%)$ & $57(74.0 \%)$ & \\
\hline
\end{tabular}

This article is protected by copyright. All rights reserved. 


\section{Figure Legend}

\section{Figure 1}

Kaplan-Meier survival curves of Individuals with Mild to Moderate and Severe Alcoholic Hepatitis. The number of participants available at each time point is shown under the X-axis.

\section{References}

Dunn, W., Jamil, L.H., Brown, L.S., Wiesner, R.H., Kim, W.R., Menon, K.V.N., Malinchoc, M., Kamath, P.S., Shah, V., 2005. MELD accurately predicts mortality in patients with alcoholic hepatitis. Hepatology 41, 353-358. https://doi.org/10.1002/hep.20503

Liangpunsakul, S., 2017. The interaction between PNPLA3 genotype and coffee drinking and the risk for acute alcoholic hepatitis.

Liangpunsakul, S., 2011. Clinical characteristics and mortality of hospitalized alcoholic hepatitis patients in the United States. J. Clin. Gastroenterol. 45, 714-719. https://doi.org/10.1097/MCG.0b013e3181fdef1d

Liangpunsakul, S., Puri, P., Shah, V.H., Kamath, P., Sanyal, A., Urban, T., Ren, X., Katz, B., Radaeva, S., Chalasani, N., Crabb, D.W., Translational Research and Evolving Alcoholic Hepatitis Treatment Consortium, 2016. Effects of Age, Sex, Body Weight, and Quantity of Alcohol Consumption on Occurrence and Severity of Alcoholic Hepatitis. Clin. Gastroenterol. Hepatol. 14, 1831-1838.e3. https://doi.org/10.1016/j.cgh.2016.05.041

Liu, F., Wang, X., Wu, G., Chen, L., Hu, P., Ren, H., Hu, H., 2015. Coffee Consumption Decreases Risks for Hepatic Fibrosis and Cirrhosis: A Meta-Analysis. PLOS ONE 10, e0142457. https://doi.org/10.1371/journal.pone.0142457

Maddrey, W.C., Boitnott, J.K., Bedine, M.S., Weber, F.L., Mezey, E., White, R.I., 1978. Corticosteroid therapy of alcoholic hepatitis. Gastroenterology 75, 193-199.

Malinchoc, M., Kamath, P.S., Gordon, F.D., Peine, C.J., Rank, J., ter Borg, P.C., 2000. A model to predict poor survival in patients undergoing transjugular intrahepatic portosystemic shunts. Hepatology 31, 864-871. https://doi.org/10.1053/he.2000.5852

Molloy, J.W., Calcagno, C.J., Williams, C.D., Jones, F.J., Torres, D.M., Harrison, S.A., 2012. Association of coffee and caffeine consumption with fatty liver disease, nonalcoholic steatohepatitis, and degree of hepatic fibrosis. Hepatology 55, 429-436. https://doi.org/10.1002/hep.24731

Orntoft, N.W., Sandahl, T.D., Jepsen, P., Vilstrup, H., 2014. Short-term and long-term causes of death in patients with alcoholic hepatitis in Denmark. Clin. Gastroenterol. Hepatol. 12, 1739-1744.e1. https://doi.org/10.1016/j.cgh.2014.04.020

Sozio, M., Crabb, D.W., 2008. Alcohol and lipid metabolism. Am. J. Physiol. Endocrinol. Metab. 295, E10-16. https://doi.org/10.1152/ajpendo.00011.2008

This article is protected by copyright. All rights reserved. 


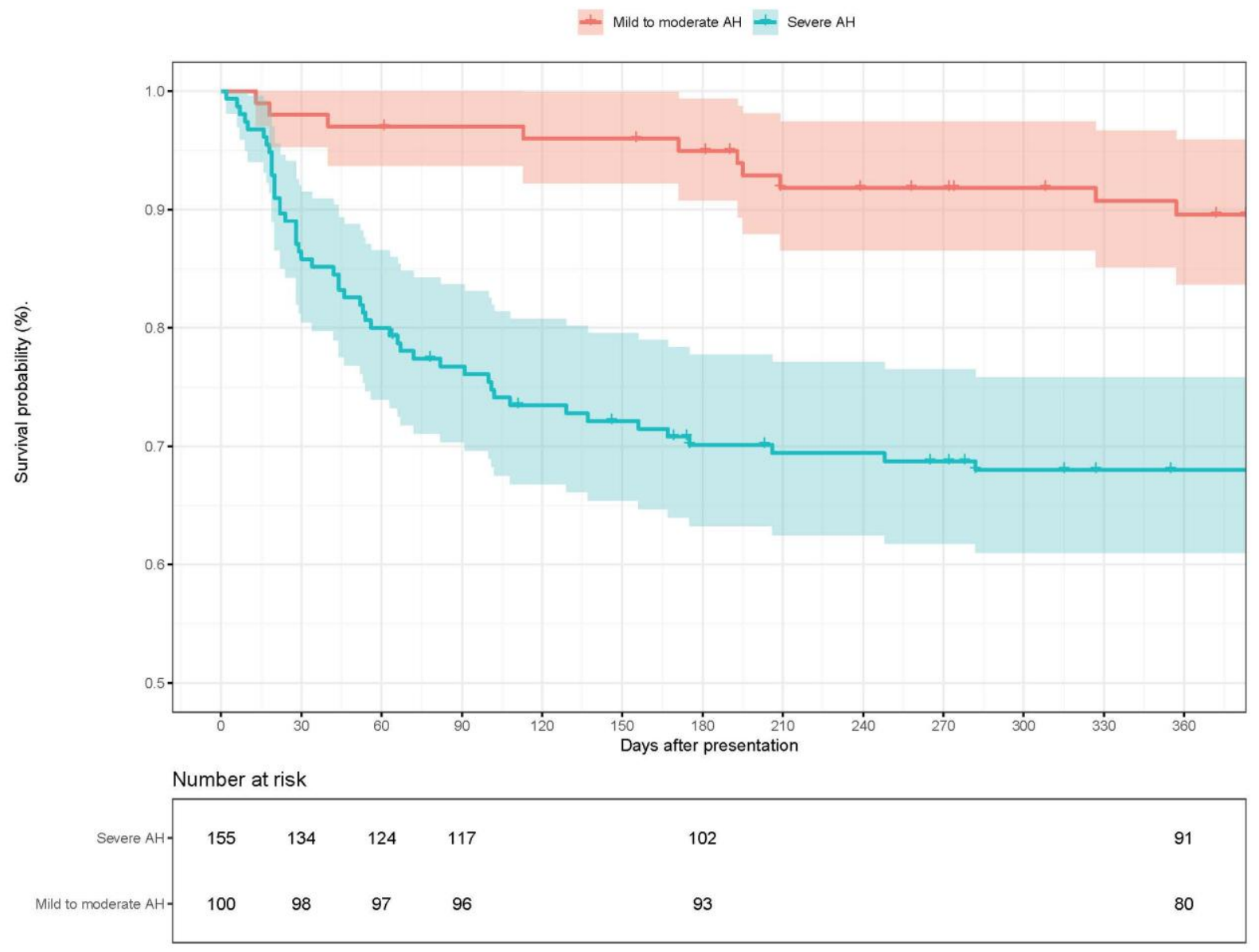

This article is protected by copyright. All rights reserved. 